\title{
Change detection in coral reef communities using Ikonos satellite sensor imagery and historic aerial photographs
}

\author{
D. PALANDRO* + , S. ANDRÉFOUËT $\dagger$, P. DUSTAN $\ddagger$ and \\ F. E. MULLER-KARGER $†$ \\ $\dagger$ Institute for Marine Remote Sensing, College of Marine Science, University of \\ South Florida, 140 7th Avenue South, Saint Petersburg, FL 33701, USA \\ $t$ Department of Biology, College of Charleston, 66 George Street, Charleston, \\ SC 29424, USA
}

(Received 12 July 2001; in final form 10 May 2002)

\begin{abstract}
For decades, aerial photographs have been the only source of very high spatial resolution data for coral reef researchers. With the launch of the Ikonos satellite in 1999, imagery with a $4 \mathrm{~m}$ spatial resolution in multispectral mode can now be combined with historical aerial photographs for change detection. We demonstrate this potential by combining two aerial photographs (1981 and 1992) and an Ikonos image (2000) to detect change in the coral reef communities for Carysfort Reef, Florida, USA. The results show a loss of 'coraldominated' bottom from $52 \%$ (1981) to $16 \%$ (1992) to finally $6 \%$ (2000), a trend similar to in situ observations.
\end{abstract}

\section{Introduction}

Representative of the changes occurring in coral reefs in the last 20 years, Carysfort Reef (Florida Keys, USA) has undergone severe live coral cover loss since 1982 principally due to disease outbreaks (Porter and Meier 1992, Dustan et al. 2001). In situ data estimated the loss in percentage terms of live coral from $50 \%$ in 1982 to $4 \%$ in 1999 . This is a decrease of $92 \%$ overall. Similar dramatic live coral losses in various regions worldwide prompted numerous monitoring activities, generally carried out using in situ survey techniques, but very few sites benefit from the long-term time series of in situ data. Conversely, regional, state and local organizations worldwide house a variety of aerial photographs (APs) at different scales and from different time periods. Aerial photography has been used extensively for mapping and change detection purposes for many years in coral reef environments (Hopley 1978, Yamano et al. 2000, Lewis 2002). With the launch of Ikonos in 1999, a satellite sensor can now provide very high spatial resolution data.

Ikonos acquires both $4 \mathrm{~m}$ spatial resolution multispectral and $1 \mathrm{~m}$ spatial resolution panchromatic data (table 1). The multispectral data consist of four bands, three in the visible (red, green and blue) and one in the near-infrared; the wavelength

*Corresponding author; e-mail: palandro@seas.marine.usf.edu

International Journal of Remote Sensing

ISSN 0143-1161 print/ISSN 1366-5901 online (C) 2003 Taylor \& Francis Ltd

http://www.tandf.co.uk/journals

DOI: $10.1080 / 0143116021000009895$ 
Table 1. Spatial and spectral properties per each Ikonos band.

\begin{tabular}{lcc}
\hline Band & $\begin{array}{c}\text { Spatial resolution } \\
(\mathrm{m})\end{array}$ & $\begin{array}{c}\text { Spectral resolution } \\
(\mathrm{nm})\end{array}$ \\
\hline Blue & 4 & $445-516$ \\
Green & 4 & $506-595$ \\
Red & 4 & $632-698$ \\
Infrared & 4 & $757-853$ \\
Panchromatic & 1 & $450-900$ \\
\hline
\end{tabular}

range of these bands is comparable to the first four bands of the Landsat Thematic Mapper (TM) and Enhanced Thematic Mapper Plus (ETM+) sensors.

In this letter, we assess the potential of Ikonos imagery combined with APs to detect change in a coral reef community, using Carysfort Reef as a case study.

\section{Methods}

Two APs acquired on 5 February 1981 and 17 January 1992 and one Ikonos image acquired on 15 October 2000 provide the basis for a multi-source change detection study of Carysfort Reef. The 1981 AP was acquired at 1:24000 scale. The $1992 \mathrm{AP}$ was acquired at 1:48 000 scale. Both APs were scanned at a spatial resolution of $300 \mathrm{dpi}$. The images were resampled to $2 \mathrm{~m}$ pixel size. Images were geo-corrected using the Ikonos image as a reference. The Ikonos image was delivered in Universe Transverse Mercator Zone 17, radiometrically corrected, by Space Imaging, Inc. No atmospheric corrections were made since classification of the images would be made from statistics acquired separately from within each image (Song et al. 2001).

An area of interest (AOI) was designated for the shallowest section of Carysfort Reef (depth of less than 1.2 m) (Dustan et al. 2001). Carysfort Reef has three distinct structural areas that are visible in each image (figure 1). These structures are defined by the darker areas within the lighter patches. There are two smaller areas in the centre (A2) and to the north (A1) of the AOI that are roughly the same size. The third area (A3) is close to twice the size of the first two and is located furthest to the south. This area contains a lighthouse tower, which can be seen as a set of black pixels in the Ikonos image.

Four classes of bottom-types represent the main benthic communities on and around Carysfort Reef. They are: 'sand', 'coral-dominated', 'bare substrate' and 'covered substrate' (table 2). Each image was studied separately to obtain training pixels for each of the four classes. The training pixels were chosen according to a large in situ database available for each year discussed. For example, in situ transect data from 1982 were overlaid onto the 1981 AP to give examples of the location of each of the four classes. A Mahalanobis Distance classifier (Venables and Ripley 1999) was applied for each image: 1981 (figure 2(a)), 1992 (figure 2(b)) and 2000 (figure $(2 c)$ ). The blue, green and red bands of the Ikonos image were the inputs of the classifier.

In situ data and protocols to measure live coral cover have been presented elsewhere (Dustan and Halas 1987). Briefly, the evaluation of live coral cover came from estimations along transects $(25 \mathrm{~m}$ wide, $300 \mathrm{~m}$ long) and four permanent Environmental Protection Agency monitoring sites. It must be stressed that in situ monitoring data provided information on live coral cover, considering individual 

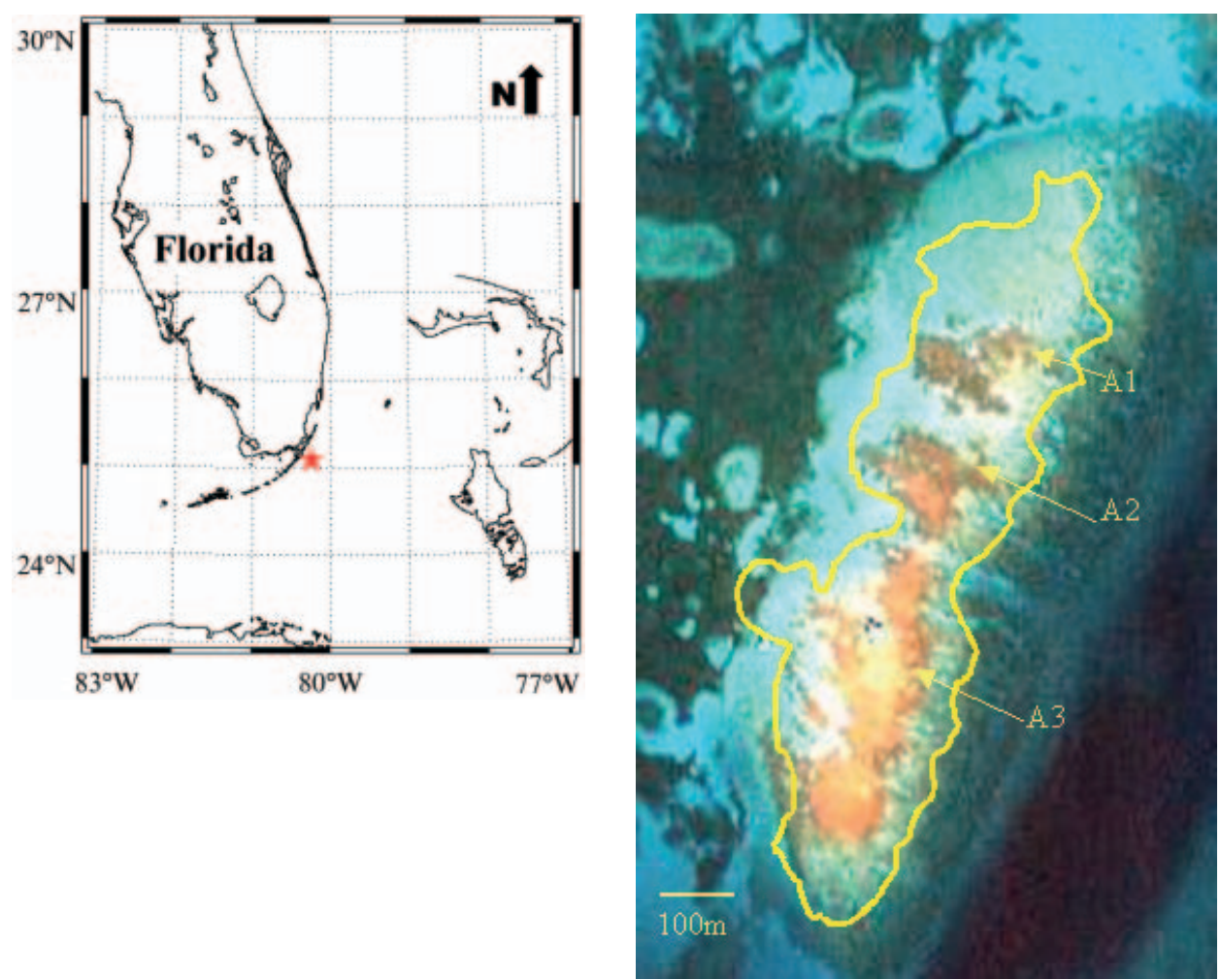

Figure 1. Location map of Carysfort Reef (red star) and Ikonos image of Carysfort Reef displaying location of the three distinct structural areas (A1, A2, A3). Carysfort Reef $\mathrm{AOI}$ is delineated in yellow.

Table 2. Components of classes used for classification. Quantification of components and characteristics within each classification.

\begin{tabular}{lll}
\hline Classes & Major components, $>50 \%$ & Minor components \\
\hline Coral-dominated & $\begin{array}{l}\text { branching, i.e. Acropora } \text { sp. } \\
\text { boulder, i.e. Montastrea } \text { sp. } \\
\text { carbonate sand }\end{array}$ & $\begin{array}{l}\text { bare substrate } \\
\text { algae } \\
\text { Sand }\end{array}$ \\
rubble \\
seagrass \\
Covered substrate & $\begin{array}{l}\text { leafed algae } \\
\text { encrusting algae } \\
\text { turf algae }\end{array}$ & substrate \\
Bare substrate & dead coral/rubble & algae \\
& & $\begin{array}{l}\text { live coral } \\
\text { sand }\end{array}$ \\
\hline
\end{tabular}

coral colonies. Conversely, remote sensing data informs on the coral-dominated area that can be mixed (table 2), at the community-scale.

\section{Results and discussion}

The three classified images provide a similar trend to that of the in situ data, i.e. a loss of community-scale 'coral-dominated' pixels (remote sensing data), and 


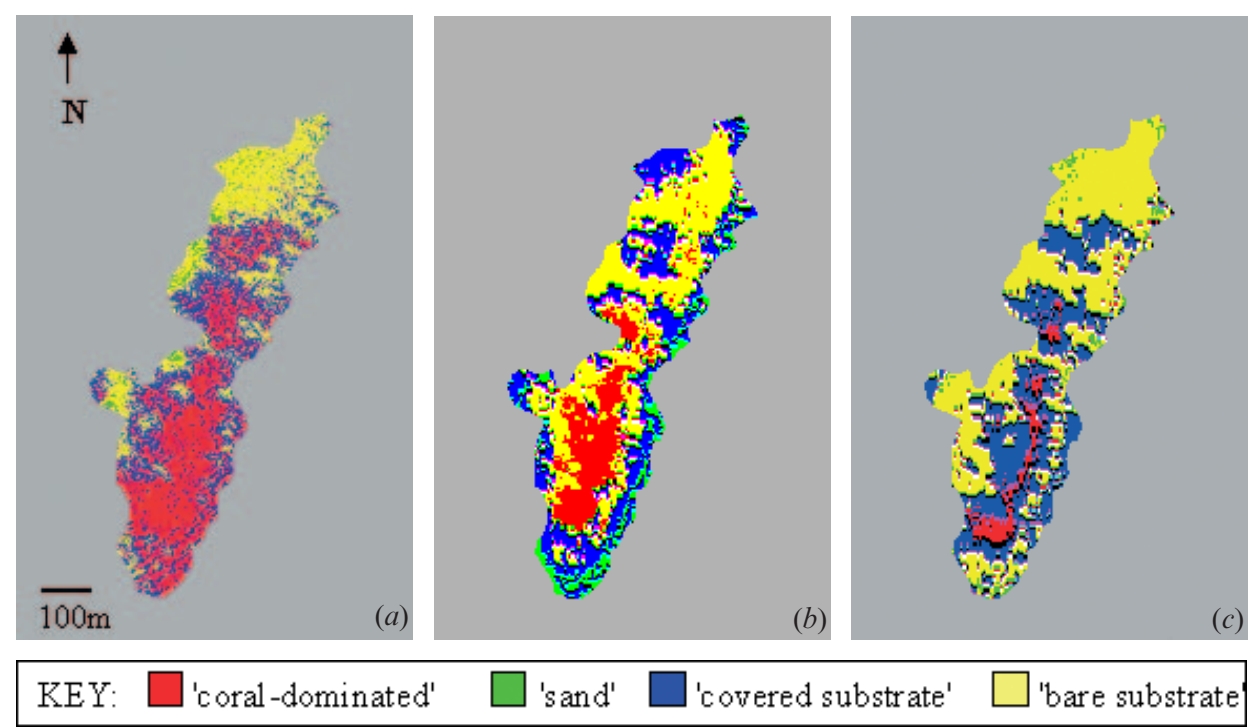

Figure 2. Mahalanobis Distance classification images of Carysfort Reef. Images are from (a) 1981, (b) 1992 and (c) 2000. A mask is placed around the Carysfort Reef AOI.

colony-scale live coral cover (in situ data). The 'coral-dominated' class, as estimated from the number of 'coral-dominated' pixels inside the AOI, declines from $52 \%$ in 1981 to $16 \%$ in 1992 to $6 \%$ in the 2000 Ikonos image (figure 3 ). This shows a total

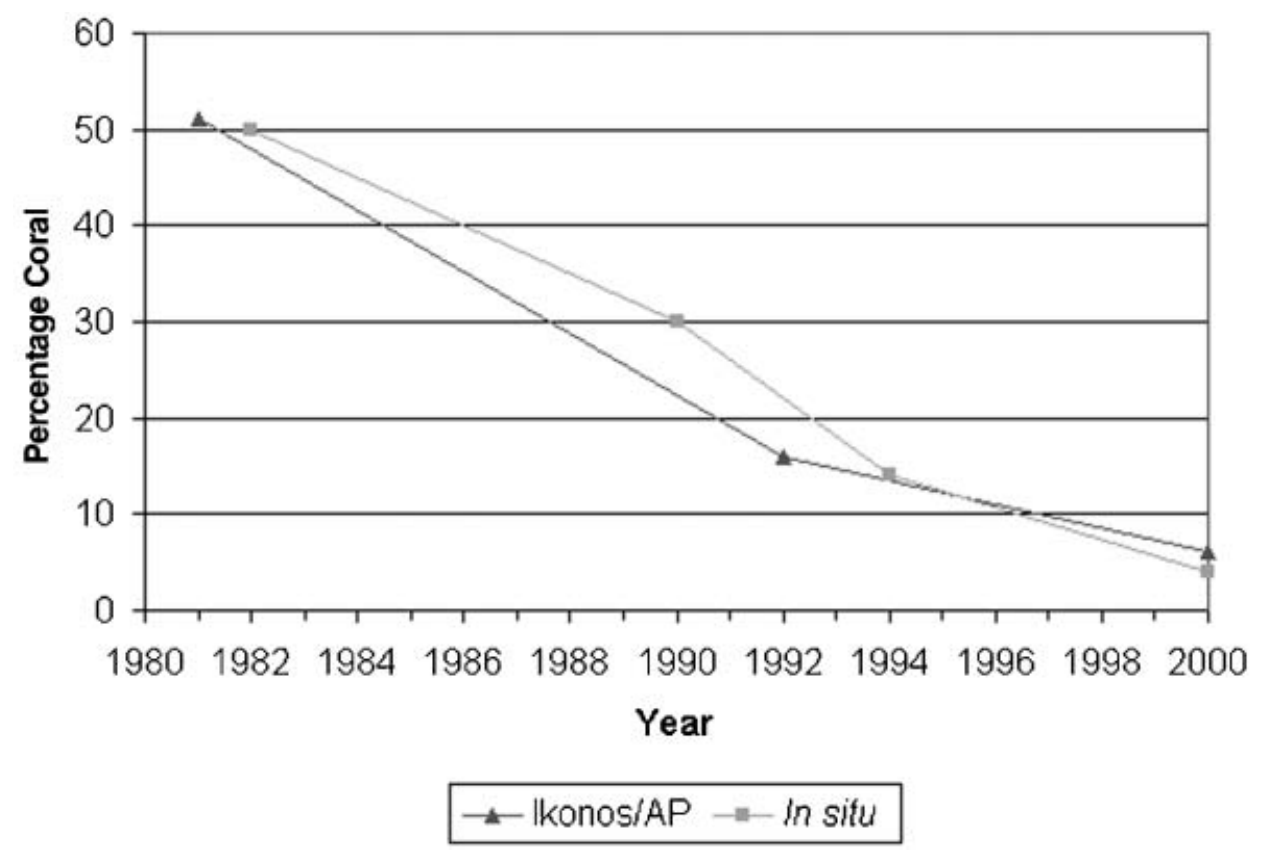

Figure 3. Live coral cover trend displayed over 19 years. Percentage of live coral cover or 'coral-dominated' pixels from aerial photography (1981 and 1992) and Ikonos image (2000) compared to in situ data. 
loss of $88 \%$ over a 19 -year time period ( $4.7 \%$ per year), for an estimated total lost area of $25650 \mathrm{~m}^{2}$. This compares well to the in situ data that demonstrate a loss of $92 \%$ over 18 years $(5.1 \%$ per year). As pointed out previously, these methods and datasets measure the coral cover at different scales, and a correlation was expected. This is confirmed by the results, that show that habitat loss is echoed by the loss of the dominant benthic feature in the same proportion.

The three structural areas mentioned above (A1, A2 and A3) can be seen more distinctly as areas largely classified as 'coral-dominated' or 'covered substrate'. The specific shape and location of the lighthouse can still be detected in the classified APs, classified as 'covered substrate' (due to its dark colour) amid a larger area of 'coral-dominated' pixels.

Loss in 'coral-dominated' bottom can be detailed spatially as follows.

- The southernmost and largest area loses the greatest level of 'coral-dominated' area to the south, east and north.

- The 'coral-dominated' pixels in this area remain centred on the location of the lighthouse.

- The centre area changes from being covered with 'coral-dominated' pixels (1981) to having nearly zero 'coral-dominated' pixels in 2000.

- The northernmost area displays a large 'coral-dominated' area in 1981 as patches east and west of the centre, to close to zero 'coral-dominated' pixels in 1992, to finally zero 'coral dominated' pixels in 2000.

- The loss of 'coral-dominated' pixels causes a shift to 'covered substrate' pixels in the subsequent image.

\section{Conclusion}

The trend of 'coral-dominated' area decline can be examined by the combination of colour aerial photography and Ikonos imagery. The direct comparison of the trends between in situ and remotely sensed results must be done carefully since in situ and remote sensing data convey information at colony and habitat scales respectively. However, both datasets highlight a consistent trend in coral decline across the same time period with similar rates of loss $(4.7 \%$ and $5.1 \%$ per year respectively).

Therefore, Ikonos imagery appears to be a relevant source of information when used in conjunction with historic colour aerial photography to show change and fragmentation in an initially compact coral reef community. The degree of generalization of this approach must be cautiously stated due to the high diversity of reef configurations worldwide.

\section{Acknowledgments}

The authors would like to thank Jim Burd of the Florida Marine Research Institute for providing the 1981 aerial photograph and Dr Bernhard Riegl of the National Coral Reef Institute for reviewing comments. Ikonos data were obtained through the National Aeronautics and Space Administration (NASA) Scientific Data Purchase Program. This work was partially supported by NASA Headquarters under the Earth System Science Fellowship Grant NGT5-30414 to David Palandro. This is IMaRS contribution 0039. 


\section{References}

Dustan, P., and Halas, J. C., 1987, Changes in the coral-reef community of Carysfort Reef, Key Largo, Florida: 1974 to 1982. Coral Reefs, 6, 91-106.

Dustan, P., Dobson, E., and Nelson, G., 2001, Remote sensing of coral reefs: detection of shifts in the community composition of coral reefs using Landsat Thematic Mapper. Conservation Biology, 15, 892-902.

Hopley, D., 1978, Aerial photography and other remote sensing techniques. In Coral Reefs: Research and Methods, edited by R. E. Johannes and D. R. Stoddart (Paris: UNESCO), pp. 23-44.

LEwIS, J. B., 2002, Evidence from aerial photography of structural loss of coral reefs at Barbados, West Indies. Coral Reefs, DOI 10.1007/s00338-001-0198-1.

Porter, J. W., and MeIER, O. W., 1992, Quantification of loss and change in Floridian reef coral populations. American Zoologist, 32, 625-640.

Song, C., Woodcock, C. E., Seto, K. C., Lenney, M. P., and Macomber, S. A., 2001, Classification and change detection using Landsat TM data: when and how to correct atmospheric effects? Remote Sensing of Environment, 75, 230-244.

Venables, W. N., and Ripley, B. D., 1999, Modern Applied Statistics with S-Plus, 3rd edn (New York, NY: Springer).

Yamano, H., Kayanne, H., YoneKura, N., and Kudo, K., 2000, 21-year changes of backreef coral distribution: causes and significance. Journal of Coastal Research, 16, 99-110. 